\title{
UMA MAQUINARIA DISCURSIVA DE RECENOGRAFAR FALAS ${ }^{\star}$
}

\author{
André William Alves de Assis \\ Universidade Federal de Minas Gerais \\ Belo Horizonte, Minas Gerais, Brasil
}

Sonia Aparecida Lopes Benites
Universidade Estadual de Maringá
Maringá, Paraná, Brasil

\begin{abstract}
Resumo: As notícias online mostram-se ricas em sobreasseverações, conceito que, de acordo com Maingueneau (2008a), implica o destaque feito pelo próprio locutor do textofonte. Não raro, no funcionamento midiático, o lugar de sobreasseverador é imputado a um locutor que não efetuou aquele destaque no texto-fonte. Mais comum, ainda, é o enunciado sobreasseverado no texto-fonte ser submetido a alterações de diversas ordens. Com o objetivo de identificar casos em que uma sobreasseveração é atribuída, à revelia, a um locutor, e categorizar as manobras discursivas visíveis nas sobreasseverações, analisamos a forma como são relatados os debates político-televisivos da Rede Bandeirantes e Rede Globo, do segundo turno das eleições de 2010, em cinco diferentes veículos online. Nossos resultados indicam a existência de manobras discursivas propiciadas pela construção da notícia online que recenografam os debates politico-televisivos.
\end{abstract}

Palavras-chave: Sobreasseveração. Citação. Notícia online. Manobra discursiva. Cenografia.

\section{CONSIDERAÇÕES INICIAIS}

É cada vez mais perceptível a crescente imbricação entre os campos político e midiático, cujas relações mútuas definem o que pode/deve circular. Nesse contexto de circulação, a política opera um discurso de poder que propõe, reivindica, denuncia, obedecendo sempre a uma lógica que produz efeitos de verdade; a mídia, por vezes, manobra o discurso político, por meio de uma sofisticada maquinaria discursiva em que está inserida, que envolve diferentes processos e agentes implicados na seleção, produção, manutenção, circulação e recepção do material veiculado.

Dessa forma, os pronunciamentos dos atores políticos, com certa frequência, dão destaque a fragmentos enunciativos curtos e singulares, destinados à repetição, que, estrategicamente situados em posição final de texto ou de parágrafo, condensam uma

\footnotetext{
* Este artigo baseia-se na dissertação Citações e sobreasseverações: o funcionamento da retomada de falas em notícias online, defendida por André William Alves de Assis, junto ao Programa de Pósgraduação em Letras (UEM), sob a orientação de Sonia Aparecida Lopes Benites.

** Doutorando em Linguística - UFMG. Email: assis.awa@gmail.com.

*** Professora Adjunta da UEM. Pós-doutora em Linguística. Email: salbenites@gmail.com.
} 
"tomada de posição". Trata-se da sobreasseveração, modalidade sobre a qual Maingueneau (2006, p. 77) assim se manifesta:

Para [...a marcação] - pela qual o autor [do texto-fonte] distingue um fragmento como destacável, que de algum modo o formata para uma virtual retomada citacional -, não podemos falar de citação nem de embrião de citação: é apenas um ato de enfatizar que se opera em contraste com o resto dos enunciados [...].

Similarmente ao que acontece aos relatos de fala, as retomadas das sobreasseverações pelos textos noticiosos apresentam, em maior ou menor grau, frequentes torções, alterações que sintetizam, ampliam, diminuem ou simplificam a enunciação-fonte. Nosso objeto de estudo neste trabalho são exatamente essas manobras discursivas, que também incidem sobre as citações em discurso direto ou indireto, e se relacionam ao posicionamento do veículo que coloca em circulação o evento enunciativo.

A consideração da materialidade linguística constitutiva das sobreasseverações nos direciona para manobras linguísticas que são, antes de mais nada, pragmáticas em seu uso, lembrando que, para Maingueneau (1996, p. 3),

existe pragmática linguística quando se considera que a utilização da linguagem, sua apropriação por um enunciador que se dirige a um interlocutor num contexto determinado, não se acrescenta de fora a um enunciado de direito autossuficiente, mas quando a estrutura da linguagem é radicalmente condicionada pelo fato de ser a linguagem mobilizada por enunciações singulares e produzir um certo efeito dentro de um certo contexto, verbal e não-verbal.

Isso não significa que o estudo aqui proposto deixe à margem da análise fatores históricos, que evidenciam o funcionamento dos diferentes discursos que emergem em nossa sociedade. Enfatizamos, contudo, a importância do material linguístico que compõe as retomadas de falas e as sobreasseverações, pois ignorá-lo implicaria deixar de explicar "os sentidos envolvidos, os fatores cruciais envolvidos em sua produção, as regras envolvidas em cada uma das interpretações, as estruturas alternativas que estão 'escondidas' em uma mesma sequência, etc.” (POSSENTI, 1996, p. 80).

As manobras efetuadas sobre as sobreasseverações presentes no corpus de análise decorrem do fato de que o discurso mantém com outro discurso uma relação polêmica, devido à interincompreensão, conceito mobilizado por Maingueneau (2008a). Esta, como esclarece Possenti (2009, p. 24),

\footnotetext{
não tem nada a ver com má vontade ou incompetência dos adversários mútuos, mas com uma característica dos discursos que brevemente pode ser assim formulada: cada discurso só pode ver o outro como um simulacro. [...] o que essa tese propõe é que todos os que têm acesso a um discurso 'de fora' compreendem-no 'erradamente' - porque o compreendem a partir de sua própria posição e não da posição dos enunciadores daquele discurso (o que implica, entre outras coisas, que para ler não basta ter acesso ao texto).
} 
Nesse contexto, propomos como objetivo geral deste trabalho analisar o tratamento dado a sobreasseverações e relatos de fala veiculados por notícias da mídia digital, utilizados para recenografar o debate político-televisivo. Nosso corpus compreende dois diferentes gêneros: dois debates televisivos entre os candidatos presidenciáveis Dilma Rousseff e José Serra, veiculados pela Rede Bandeirantes (BAND) e Rede Globo (GLOBO), no segundo turno das eleições para presidência do Brasil, do ano de 2010; notícias de jornais online sobre o referido debate, veiculadas por Carta Capital, Band, Época, Uol, Veja e Terra.

Os objetivos específicos consistem em descrever as manobras utilizadas para interpretar e alterar as sobreasseverações e os relatos de fala nas notícias online, e, dessa forma, observar se essas manobras recenografam os debates político-televisivos, modificando ou criando novas cenografias que são, em sua maioria, destoantes daquelas construídas pelo ator político em forma de sobreasseveração.

A pesquisa iniciou-se pela delimitação do material teórico e de nossa posição em relação ao conceito de sujeito, nos termos de Maingueneau (2008a), que mobiliza o conceito de competência discursiva, referente a um saber e agir sobre a língua que "permite esclarecer um pouco a articulação do discurso e a capacidade dos Sujeitos de interpretar e de produzir enunciados que dele recorram" (MAINGUENEAU, 2008b, p. 52).

Metodologicamente, descrevemos, inicialmente, os debates e levantamos as ocorrências de alterações nas citações e sobreasseverações das notícias online que nos servem de corpus. Posteriormente, tabulamos as ocorrências de alterações sobre um mesmo excerto dos debates político-televisivos. $\mathrm{Na}$ análise, verificamos, com especial atenção, se as sobreasseverações foram mesmo construídas na enunciação-fonte ou se foram a ela atribuídas e/ou modificadas pelo texto da notícia, se a fala do ator político ou mesmo toda a enunciação é reconstruída por diferentes cenografias na notícia online. O referencial teórico em que nos ancoramos assenta-se nos estudos de autores como Maingueneau (1996, 1997, 2006, 2008a, 2008b, 2011a, 2011b), e em estudiosos do Centro de Pesquisa Fórmulas e Estereótipos: Teoria e Análise (FEsTA), entre outros que levantam conceitos fundamentais para a pesquisa proposta.

De forma a organizar nosso percurso, levantamos, inicialmente, uma discussão em torno da heterogeneidade da maquinaria midiática, que coloca fatos em circulação por meio do jornalismo online. Problematizamos os conceitos de sobreasseveração, cenografia e ethos, uma vez que no processo de produção da notícia online, as alterações nas citações e sobreasseverações se manifestam como prática discursiva dessa maquinaria midiática. Posteriormente, reunimos informações sobre a constituição e as condições de produção de nosso corpus. Por fim, apresentamos nossa análise e nossas possíveis contribuições em torno dessa reflexão sobre o funcionamento das citações e sobreasseverações em notícias online. 
Os dados analisados neste trabalho situam-se no campo do jornalismo online, especificamente no gênero ${ }^{1}$ notícia, cuja produção se insere na maquinaria discursiva que envolve o universo da mídia ${ }^{2}$. As notícias focalizadas tematizam relatos de fala dos candidatos à presidência da República, durante um debate televisivo do segundo turno das eleições de 2010. Embora mobilizemos também o gênero debate político-televisivo, enquanto acontecimento sócio-histórico, o foco do trabalho são as notícias online que os relatam.

A compreensão do funcionamento da notícia referente à atribuição a outrem de um dizer, seja ela impressa ou online, pressupõe que se leve em conta o funcionamento dessa maquinaria discursivo-midiática em que intervêm fatores e atores diversos, sistemicamente inter-relacionados e envolvidos na obtenção, triagem, interpretação e circulação das informações.

As características dos discursos resultantes da maquinaria midiática, como de resto de qualquer discurso, devem-se à natureza da linguagem, constitutivamente heterogênea. Na perspectiva de Authier-Revuz (1982, p. 141, tradução nossa, grifos nossos), sujeito e discurso são constitutivamente heterogêneos, e todo discurso se mostra "constitutivamente atravessado pelos 'outros discursos' e pelo 'discurso do Outro'. O outro não é um objeto (exterior; do qual se fala), mas uma condição (constitutiva; pela qual se fala)"; a homogeneidade não passa de ilusão. A máquina midiática também é heterogênea na sua constituição e em suas práticas. Essa maquinaria engloba as práticas de jornalistas e de grande número de profissionais relacionados à produção da notícia, o meio (digital, impresso, radiofônico, televisivo...), os motivos que levam à produção da notícia (novidade, relevância, contingente de pessoas atingidas $^{3}$ pelo acontecimento), suas diferentes etapas de circulação e atividades não profissionais, como o caso de leitores, que comentam as notícias, por exemplo ${ }^{4}$.

Porém, quem assegura, em maior parte, a saúde financeira da mídia são os anunciantes, que também pertencem à engrenagem midiática. Seu investimento financeiro não se relaciona somente com a publicização de uma propaganda, de uma marca, de um projeto, etc. Por ser a base financeira da maquinaria midiática, os anunciantes muitas vezes "fazem pressão sobre a mídia, de diversas maneiras, para que esta apague a fronteira entre anúncio e informação" (BERTRAND, 1999, p. 44), controlando-a, manipulando-a, fazendo-se ouvir.

\footnotetext{
${ }^{1}$ Gêneros discursivos compreendidos na perspectiva de Bakhtin (2003) como enunciados relativamente estáveis em suas proporções discursivas e dialógicas determinadas sócio-historicamente.

${ }^{2}$ Uma vez que "cabe ao analista definir, em função de seus objetivos, os recortes genéricos que lhe parecem pertinentes" (MAINGUENEAU, 1997, p. 35), consideramos, metodologicamente, a mídia como universo, o jornalismo online como campo e a notícias online como gênero.

3 O público-alvo da notícia online, os "usuários" (BERTRAND, 1999), são sujeitos que a mídia online intenciona alcançar com seus materiais, ou que supostamente compreendem um todo definido como "público-alvo", afetos de um ou outro meio de comunicação (assinantes ou leitores de uma revista ou jornal, telespectadores, ouvintes ou internautas).

${ }^{4}$ No caso da mídia online, esses comentários assumem especial relevância, uma vez que a resposta do leitor é imediata e tem reflexos na (re)construção do texto e em suas formas de recepção.
} 
Dessa forma, mesmo que seja dado como o responsável pela informação, o jornalista representa tão somente uma parte da engrenagem de toda a maquinaria midiática. É o que afirma, enfaticamente, Charaudeau (2012, p. 74), para quem "nunca se sabe realmente quem pode responder por uma informação, mesmo quando é assinada por um determinado jornalista". Com efeito, esse funcionamento das peças da maquinaria é tão sistematicamente organizado que fica difícil saber quem realmente deve responder por ela. O que se pode afirmar é que o jornalista, em sua prática discursiva, não cria as notícias; dá-lhes um tratamento e as coloca em circulação.

Nesse sentido, tomamos como responsável pela notícia o veículo de comunicação, da mesma forma que o responsável pela embalagem de um produto ${ }^{5}$ é a empresa que o fabrica e o comercializa. Tanto é assim que, em ambos os casos, a empresa é que será processada, no caso de informação falsa ou equivocada. É dela a palavra final sobre a seleção, a organização, o tom e a disposição espacial das informações a serem levadas a público, segundo critérios por ela decididos. Isso não significa que seu discurso seja homogêneo ou uniforme, pois, como vimos enfatizando, envolve setores e profissionais diversos e essa homogeneidade é, na verdade, uma ilusão.

A maquinaria midiática de que vimos falando direciona o fazer, a prática dos meios de comunicação ${ }^{6}$, define o que e como se pode dizer. Nesse vasto universo midiático, direcionamos um olhar para campo do jornalismo, e, especificamente, para o gênero notícia online. Esclarecemos que, embora o adjetivo possa produzir um sentido de novidade para o substantivo 'notícia', relacionamos intimamente esse gênero com a notícia em geral, que se insere no campo do jornalismo, pertencente a essa maquinaria midiática. Para que possamos lançar um olhar sobre o funcionamento da notícia online, é necessário observá-la em suas condições de emergência, no âmbito social e histórico em que se insere dentro dessa maquinaria.

\section{SOBRE ASSEVERAÇÃO, CENOGRAFIA E ETHOS}

Vimos anteriormente que a sobreasseveração está inscrita nas práticas discursivas da maquinaria midiática que envolve a produção de notícias online. Os enunciados que perpassam esse processo constroem a notícia, por meio de uma encenação que envolve o discurso relatado. Esses relatos, por sua vez, constroem redes de sentidos que compõem essas notícias. Nesse contexto, a situação de enunciação e a cena da enunciação de uma notícia online não se confundem.

De acordo com Maingueneau (2006, p. 250), a situação de enunciação, também compreendida como situação de comunicação, considera "o processo de comunicação, de certo modo, 'do exterior', de um ponto de vista sociológico", são as condições de produção de um discurso. Em contrapartida, a cena da enunciação considera o processo de comunicação “'do interior”, mediante a situação que a fala pretende definir, o quadro

\footnotetext{
${ }^{5}$ Exemplo dado por Possenti (2009, p. 48), a propósito da relação linguagem/sujeito.

${ }^{6}$ Comunicação neste trabalho é compreendida como "a antecipação das práticas de retomada, de transformação e de reformulação dos enunciados e de seus conteúdos” (KRIEG-PLANQUE, 2011, p. 26), ou seja, compreendida em uma perspectiva discursiva.
} 
que ela mostra (no sentido pragmático) no próprio movimento em que se desenrola" (2006, p. 250).

Nesse contexto, a cena da enunciação a que Maingueneau (2011b) se refere compreende três cenas de fala distintas, que se complementam:

a) "cena englobante", definida pelo tipo de discurso;

b) a "cena genérica", definida pelo gênero;

c) a "cenografia" que legitima o discurso.

A cena englobante atribui ao discurso seu caráter pragmático e corresponde ao tipo de discurso (jurídico, político, midiático, etc.) do texto; "[...] é ela quem define a situação dos parceiros em certo quadro espaço-temporal" (MAINGUENEAU, 2011a, p. 86).

Quando se recebe um folheto na rua, deve-se ser capaz de determinar se é membro do discurso religioso, político, publicitário etc., em outras palavras, em que cena englobante se deve situá-lo para interpretá-lo, em nome de que ele interpela aquele que o recebe.

(MAINGUENEAU, 2006, p. 251)

Em relação ao nosso corpus, as notícias online abrangem as cenas englobantes envoltas no discurso político, na medida em que reúnem enunciados organizados em torno do debate político-televisivo. Entretanto, não é apenas um tipo de discurso que emana dessa cena englobante; o discurso jurídico e o midiático afetam, mais ou menos, o discurso que prevalece, o político. Nesse sentido, a cena englobante permite observar, por meio do tipo do discurso, o posicionamento do jornal ou revista online. Contudo, a cena englobante "não é suficiente para especificar atividades verbais" (2006, p. 251), pois o texto é sempre enunciado por meio de um gênero, que compreende outra cena de fala, a genérica.

A cena genérica está relacionada com o gênero discursivo, que envolve "um contexto específico: papéis, circunstâncias (em particular, um modo de inscrição no espaço e no tempo), um suporte material, uma finalidade etc." (MAINGUENEAU, 2008a, p. 116). Em síntese, as condições de enunciação do debate político-televisivo definem os papéis do moderador, dos atores políticos e do público (o eleitor); as condições de enunciação da notícia online definem os papéis do enunciador, do jornalista e de um interlocutor (o leitor da notícia). Em ambos, as condições de enunciação definem os rituais, os papéis, o lugar de circulação da enunciação, assim como o tempo em que podem ser utilizados, os papéis de cada uma dentro da cena genérica.

Dessa forma, cada gênero corresponde "a certo número de expectativas do público e de antecipações possíveis dessas expectativas pelo autor" (MAINGUENEAU, 2006, p. 251), o que possibilita a manutenção das relações sociais, sem que seja necessário que a cada situação de comunicação seja criado um novo gênero; "um sujeito ao enunciar presume uma espécie de 'ritual social da linguagem' implícito, partilhado pelos interlocutores” (MAINGUENEAU, 1997, p. 30); esse ritual compreende a cena genérica. 
Essas duas primeiras cenas compreendem, em muitos casos, o que se entende por cena da enunciação, uma vez que, segundo Maingueneau (2011a, p. 87) "definem conjuntamente o que poderia ser chamado de quadro cênico do texto. É ele que define o espaço estável no interior do qual o enunciado adquire sentido - o espaço do tipo e do gênero de discurso". No entanto, não é com esse quadro cênico que compreende as cenas englobante e genérica que o leitor se depara na enunciação, e sim com uma terceira cena. Trata-se da cenografia, "a qual não é imposta pelo tipo ou pelo gênero de discurso, sendo instituída pelo próprio discurso" (MAINGUENEAU, 2008a, p. 116). Dessa forma, é o próprio discurso que impõe uma cenografia, que já se constrói pela busca de convencer seus interlocutores e instituir essa cena de enunciação para se legitimar.

\begin{abstract}
O leitor se vê assim apanhado numa espécie de armadilha, porque o texto lhe chega em primeiro lugar por meio de sua cenografia, não de sua cena englobante e de uma cena genérica, relegadas ao segundo plano, mas que na verdade constituem o quadro dessa enunciação. (MAINGUENEAU, 2006, p. 252)
\end{abstract}

Para que a cenografia se legitime, é necessário que o discurso faça com que os lugares por ele estabelecidos na cena genérica sejam aceitos por seus leitores; a cenografia implica a presença de duas figuras: o enunciador e seu correlato, o coenunciador". O leitor se vê em uma cena a que o discurso lhe atribuiu, "é por intermédio de sua própria enunciação que ele [o discurso] poderá legitimar a cenografia que ele impõe" (MAINGUENEAU, 2008a, p. 117).

Diretamente relacionado ao conceito de cena da enunciação está o conceito discursivo de ethos.

Nesse sentido, Maingueneau (2011b) apresenta sua noção de ethos em uma dimensão discursiva e não apenas como uma imagem exterior de um enunciador. Para o autor, o ethos se desdobra no registro do "mostrado", eventualmente no do "dito", e a sua eficácia decorre, de alguma forma, do envolvimento com a cenografia, com a enunciação, sem que isso seja explicitado no enunciado (MAINGUENEAU, 2011b). Essa visão de ethos nos permite evidenciá-lo não só em textos orais, mas também em textos escritos, o que sugere uma ruptura entre esse conceito de ethos com o conceito de ethos da retórica clássica ${ }^{8}$.

As noções de ethos e de cena da enunciação, estudadas ao longo dos anos por Maingueneau, são também relevantes para que possamos lançar um olhar discursivo em

\footnotetext{
${ }^{7}$ De acordo com Maingueneau (2011a, p. 70), o enunciador deve pressupor que seu destinatário respeita as "regras do jogo", assumindo os papéis a ele estabelecidos na cena genérica. Como não se trata de um sujeito passivo, considera-se coenunciador esse sujeito que participa ativamente da enunciação que se constrói interativamente no discurso.

${ }^{8}$ Citelli (1994) lembra que a preocupação com o domínio da expressão verbal nasceu entre os gregos, daí a larga tradição dos tribunos, dos sofistas que acreditavam ser a argumentação oral resultado de muita prática; iam às praças, aos foros, aos tribunais com a pretensão de alterar pontos de vista, mudar conceitos pré-formados, etc. Ainda na Grécia, as escolas tinham disciplinas para ensinar a arte do domínio da palavra, tamanha a preocupação com a estruturação do discurso, do falar de modo elegante e convincente, unindo arte e espírito. Coube à retórica clássica ensinar a forma "correta" de construir um discurso com vistas ao convencimento do interlocutor e à criação de uma imagem de seu enunciador.
} 
relação aos debates televisivos e às notícias online. Partindo do princípio de que "o ethos se mostra, ele não é dito" (MAINGUENEAU, 2011b, p. 71), o autor estabelece um novo percurso para o termo, extrapolando a noção aristotélica de ethos voltado à eloquência, ao propor que

\begin{abstract}
qualquer discurso escrito, mesmo que a negue, possui uma vocalidade específica, que permite relacioná-lo a uma fonte enunciativa, por meio de um tom que indica quem o disse: o termo "tom" apresenta a vantagem de valer tanto para o escrito quanto para o oral: podese falar do "tom" de um livro. (MAINGUENEAU, 2011b, p. 72)
\end{abstract}

Neste trabalho, a noção de "tom" é de suma importância para pensarmos ethos e cenografia no funcionamento da sobreasseveração, pois esses enunciados materializamse em notícias online que se constroem por meio de uma cenografia. Para Amossy (2011, p. 16), "se cada tipo de discurso comporta uma distribuição pré-estabelecida de papéis, o locutor pode escolher mais ou menos livremente sua cenografia". Nessa cenografia, a vocalidade a que Maingueneau (2011b) se refere está relacionada com a determinação do corpo de um enunciador e não efetivamente com o corpo do autor de um discurso, uma confluência indissociável entre tom, caráter e corporalidade ${ }^{9}$, que recobrem o campo do ethos discursivo imanente da cena da enunciação.

O posicionamento de cada veículo de informação restringe, conscientemente ou não, as escolhas que envolvem todo esse processo de construção/manutenção da cena da enunciação. São coerções da maquinaria discursivo-midiática que envolvem todas as peças da engrenagem, consequentemente seus produtos, como as notícias online.

\title{
4 A NOTÍCIA ONLINE
}

Em uma sociedade em que se instituiu uma necessidade diária de urgência, a velocidade da internet consolidou um campo gigantesco e gerador de produtos/serviços em que circulam informações dos mais variados tipos, materializados em diferentes gêneros discursivos, pertencentes aos mais variados campos.

A rapidez da internet, junto às imensas possibilidades de comunicação, associouse ao jornalismo online, o que permitiu maior visibilidade das informações em rede, com amplos resultados no que diz respeito à apuração dos fatos e à transformação destes em notícia. Isso fez com que a internet interferisse no processo de produção do jornalismo contemporâneo, que teve que se adequar a esse novo (ciber)espaço.

\footnotetext{
Em menos de cinco anos de funcionamento da internet, aquela noção de ordem e de rotina produtiva ditada pelos meios industriais - em que o trabalho do repórter é apenas uma etapa na cadeia de produção que termina nas rotativas e na distribuição do produto ao leitor - foi subvertida pelo ritmo frenético do noticiário no ciberespaço, que passou a buscar a instantaneidade para a mensagem jornalística escrita. (MARTINEZ, 2010, p. 15).
}

\footnotetext{
${ }^{9}$ De acordo com Souza-e-Silva (2012) "tom, caráter e corporalidade provêm de um conjunto difuso de representações sociais valorizadas ou desvalorizadas sobre as quais se apoia a enunciação".
} 
Em meio às mudanças impostas pela internet, grandes revistas, jornais e outros meios de comunicação passaram a produzir um webtrabalho, nesse lugar em que a notícia acompanha a imediatez característica da mídia online, produzindo o efeito de que a informação está sempre ao alcance da mão.

De acordo com Nogueira (2003, p. 160),

de certo modo, a lógica do tempo informativo entrou, nas diversas instâncias e para os diversos agentes do espaço público, numa era de quase imediaticidade absoluta. Os utensílios de mediação permitem tempos cada vez mais curtos no cumprimento do ciclo comunicacional.

É nesse contexto que se encontra nosso corpus, composto por notícias online, gênero discursivo ${ }^{10}$ que pertence à ordem do relatar (DOLZ; SCHNEWLY, 2004), portanto, atrelado ao regime textual em que se insere a sobreasseveração. Essas notícias, de acordo com qualquer manual de jornalismo, teriam a finalidade primeira de serem "claras, imparciais e esclarecedoras dos acontecimentos sociais". O jornalismo online, ao reproduzir os acontecimentos da última hora, seleciona-os e elabora a notícia, interferindo, durante esse processo, no funcionamento das citações e sobreasseverações que são constitutivas dessa notícia.

A notícia online possui características específicas que a diferenciam da notícia impressa. Entre as diferentes características que podemos encontrar em nosso corpus $^{11}$, as mais recorrentes são: a hipertextualidade, que abre a possibilidade de se aprofundar na notícia em diferentes textos ou mesmo arquivos multimídia como áudio e vídeo; a interatividade, que possibilita ao leitor interferir no ambiente em que a notícia online é veiculada, ou mesmo interagir com o autor e os demais leitores; a multimidialidade, que pode ser observada pela convergência entre a notícia (fato social) e os dois elementos anteriores. Essas características não são estanques, tampouco únicas. Uma página de internet de jornal ou revista pode trazer essas características tanto no layout da página em que a notícia é inserida, quanto no seu próprio corpo. O que podemos afirmar é que não há páginas de internet que veiculam notícias totalmente estáticas, como observa Nogueira (2003, p. 164-165), pois a notícia do periódico online exibe a

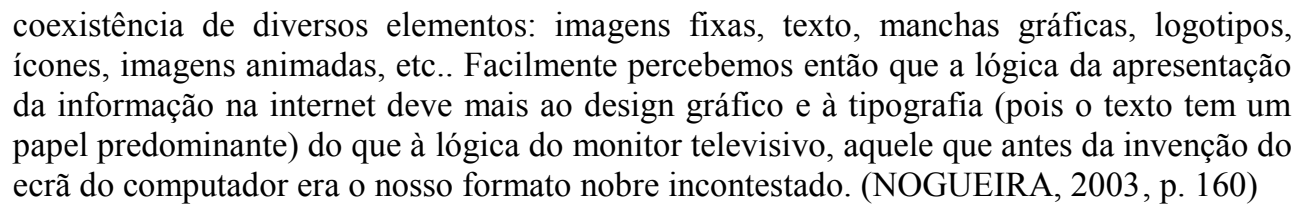

Uma das características da notícia online é fazer emanar, a partir dessa notícia "tronco", na velocidade do seu acontecimento, notícias laterais, que são "os galhos" interligados por meio de outra característica da notícia online, os hiperlinks, dispostos

\footnotetext{
10 Tratamos a notícia como gênero, embora não seja nosso interesse neste trabalho descrever tema, composição e estilo da notícia online. Interessa-nos, portanto, mostrar brevemente algumas características dessa notícia online, que permitem explicar o processo de sobreasseveração.

${ }^{11}$ As características reunidas aqui são gerais, e podem não ocorrer em todas as notícias online.
} 
na página em que as notícias são veiculadas. Esses hiperlinks são caminhos que direcionam os leitores às notícias disponíveis, permitindo ao usuário ir e vir, optar por caminhos diferentes de leitura entre os "galhos" possíveis. Os hiperlinks podem também direcionar seu leitor a recursos multimídia, como vídeos, áudios, imagens, etc., que compõem toda a página em que a notícia é inserida.

Figura 1 - Layout de uma notícia online

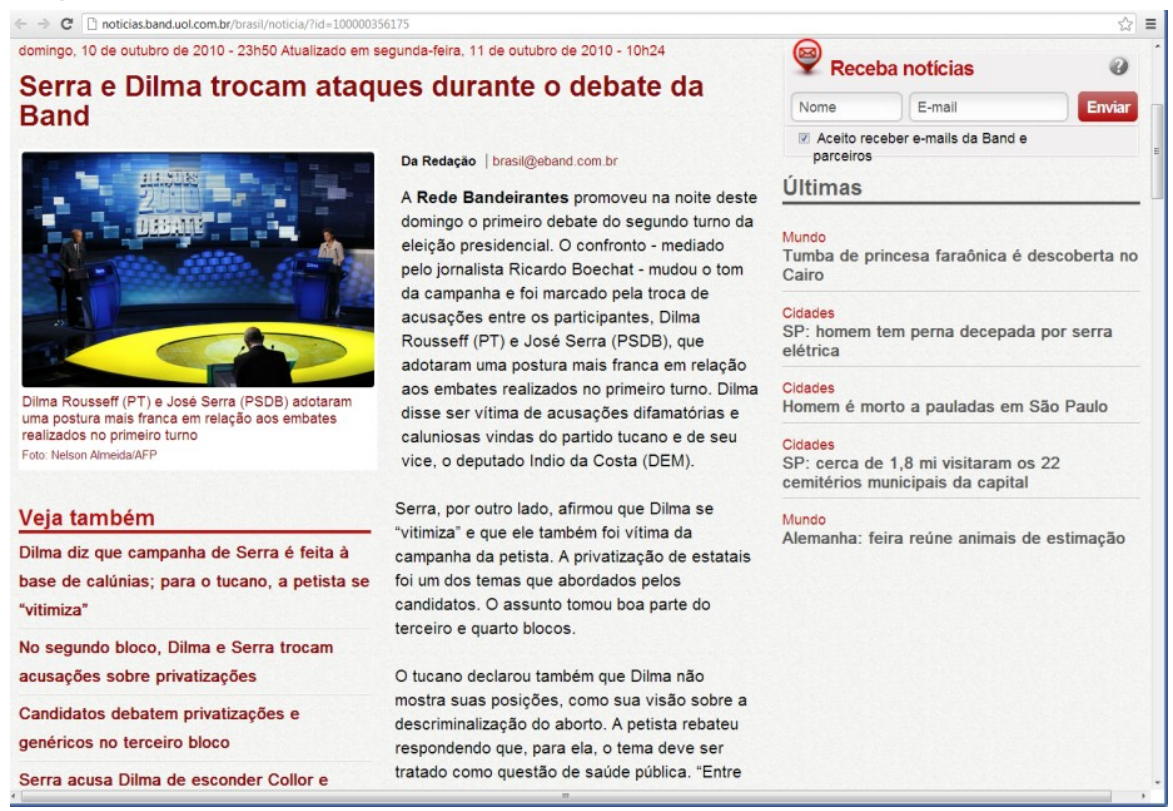

Fonte: Disponível em: http://noticias.band.uol.com.br/brasil/noticia/?id=100000356175. Acesso em: 02 jun. 2012

As notícias online que nos servem de corpus não possuem links direcionados a vídeos; algumas possuem "galhos" que compõem, como vemos na figura 1, abaixo do título "Veja também", a "árvore de notícias". Essas características podem ser mais ou menos acentuadas nos diferentes meios de comunicação que publicam notícias online. No entanto, o tratamento dado à sobreasseveração feita pelo autor da fala relatada nos parece ter papel fundamental no processo de construção de todas as notícias online que nos servem de corpus, o que nos permite observar esse processo como característica desse gênero.

Para que possamos compreender como a maquinaria midiática constrói o gênero notícia online por meio da intervenção no processo de sobreasseveração de relatos de falas, que envolve especificamente um movimento de destextualização entre as modalidades da língua falada (no debate político-televisivo) e escrita (na notícia online), passamos à análise.

\section{ANÁLISE}

O percurso teórico realizado até o momento exigiu de nós algumas escolhas que trazem resultados importantes para a pesquisa. Antes de proceder à análise, resgatamos nossos objetivos, deixando claro que nos interessa, neste trabalho, analisar a abordagem 
dada pela notícia online à sobreasseveração, focalizando, especificamente, as manobras a que é submetido o enunciado sobreasseverado no texto-fonte ao ser citado nas notícias online. Neste caso, procuramos caracterizar tais alterações, sem a finalidade de fechar a compreensão nessas categorias, mas sim de forma a possibilitar um aprofundamento da análise. Essa opção é metodológica.

É possível que a análise e os exemplos levantados demonstrem que algumas manobras estão intimamente ligadas; ou que, em um mesmo enunciado, identifiquemos manobras distintas ou complementares. A identificação dessas manobras nos permite observar de forma categorizada como se processa o funcionamento discursivo desses enunciados que saem de um contexto onde significam para ressignificar em outro.

\subsection{TÍTULO COMO TOMADA DE POSIÇÃO}

As falas destacadas do debate são submetidas a procedimentos de editoria por parte da maquinaria midiática e, mesmo quando reprisadas em seu meio de origem (neste caso, a televisão), sofrem cortes e justaposições que lhes alteram o significado. Esse procedimento é ainda mais visível quando se trata de uma passagem do texto falado para o escrito. É o caso de manchetes, olhos ou títulos, exemplos de sobreasseverações que, ao se propor resumir o evento, pelo recurso ao discurso indireto, assumem uma posição avaliativa do desempenho dos participantes e do debate, como um todo. Nas publicações de notícias online, consideramos que o título da notícia é uma manifestação de tomada de posição, pois a síntese que elabora mostra-se como uma forma de chamar a atenção do leitor ao que pode ser um resumo do confronto discursivo veiculado pela TV.

A tomada de posição está relacionada à cenografia construída em torno da notícia e se evidencia logo no título de cada uma das notícias que compreendem nosso corpus. Vejamos:

(1)

CARTA CAPITAL: No $1^{\circ}$ debate, Dilma reage e dá novo tom à campanha no $2^{\circ}$ turno.

BAND: Serra e Dilma trocam ataques durante o debate da Band.

UOL: Petistas comemoram e tucanos criticam estratégia de Dilma.

VEJA: Debate na televisão renasceu neste domingo.

TERRA: No debate mais duro da eleição, Dilma e Serra trocam acusações.

Os títulos em (1) representam uma tomada de posição do jornal em relação ao debate televisivo, ao mesmo tempo em que instituem uma cenografia e trazem pistas sobre qual será o tom da notícia sobre o debate. Nesse sentido, já podemos observar que cada título constrói uma cenografia, que será sustentada e validada por diferentes elementos na construção da notícia online. Algumas escolhas lexicais dos títulos são evidências da cenografia, do tom que será dado à interpretação por cada veículo de informação em relação ao que foi apresentado no debate televisivo; todos eles em forma de resumo, de síntese. 
Em (1), sem destacar candidatos, VEJA, em seu título, sobreassevera o evento político como o renascimento do debate televisivo, sem dar mais informações para o leitor. A dúvida fica em torno do motivo desse renascimento e de quem teria se saído melhor no debate, o que chama a atenção do leitor e, de certa forma, leva-o a ler a notícia para compreender o título. $\mathrm{O}$ que podemos observar é que, ao optar por não destacar o desempenho de um ou outro candidato no embate, VEJA se apresenta com um ethos de isenção e neutralidade, em relação aos demais títulos resumitivos do debate. Esse ethos pode ser uma forma de cativar o leitor que vê nessa manobra a isenção de posicionamento do veículo, atribuindo a todo o texto essa qualidade, o que, veremos, não acontece.

Ao contrário de VEJA, os outros quatro veículos põem em relevo uma tomada de posição menos neutra. CARTA CAPITAL sobreassevera o debate como uma reação que resulta em "novo tom" da campanha, em consequência da reação de Dilma Rousseff. O título sugere pelo menos duas possíveis inferências: a primeira, de que Dilma não estava, até o momento do debate, em posição confortável ou de vitória, uma vez que há uma reação dela no debate; a segunda, de que a campanha possuía, até então, um tom diferente, supostamente favorável a Serra, e que agora é Dilma quem dá o "novo tom à campanha". O UOL, assim como CARTA CAPITAL, sobreassevera que Dilma Rousseff fora vencedora, ao trazer em seu enunciado que "Petistas comemoram". Se há comemoração, podemos concluir que a estratégia escolhida foi vitoriosa, o que se estende aos petistas e a sua candidata. Ainda, no mesmo enunciado de UOL, temos que "tucanos criticam estratégia de Dilma", enunciado que abre a possibilidade de interpretação de que José Serra teria perdido o debate e, posteriormente à derrota, seus correligionários teriam criticado a estratégia de Dilma Rousseff.

A BAND não põe em evidência um único candidato, como fizeram CARTA CAPITAL e UOL, e destaca tanto Dilma quanto Serra. No entanto, o jornal sobreassevera como "ataque" o debate entre os dois atores políticos, já direcionando a cenografia de luta que será construída no discurso. TERRA tem a mesma posição da BAND e põe em relevo os dois candidatos, direcionando a interpretação para uma troca de acusações entre os candidatos, o que teria resultado em um debate "mais duro". De certa forma, a cenografia de batalha que se constrói no TERRA está relacionada à cenografia de disputa e luta da BAND.

Todos esses exemplos de títulos das notícias online que nos servem de corpus evidenciam, em maior ou menor grau, o posicionamento de cada veículo em relação ao acontecimento enunciativo do debate veiculado pela BAND. Tanto aqueles que não se posicionaram de forma clara no título quanto aqueles que já se posicionam intensificarão seu posicionamento no desenvolvimento do texto, em grande parte por meio de manobras efetuadas em sobreasseverações que se agrupam na construção discursiva da notícia online.

Como já observamos, os títulos em (1) são interpretações que se processam por um movimento de síntese da enunciação do debate e constroem cenografias diversas por meio de um tom que se sustenta no discurso. A tomada de posição logo no título, primeiro elemento da notícia, permite-nos pensar no tipo de posicionamento que essas escolhas, que silenciam tantas outras, podem evidenciar. Levam-nos a questionar também quais são os tipos de sobreasseverações estão sendo ali reunidas, uma vez que temos no título um resumo que, ao mesmo tempo, constrói uma cenografia e marca 
posicionamentos favoráveis e desfavoráveis aos candidatos. Algumas pistas, escolhas lexicais, a opção por evidenciar ou apagar os sujeitos políticos já nos direcionam para algumas interpretações possíveis de quais podem ser os posicionamentos que cada uma das revistas assume no discurso, pois o tom por elas empregado na sobreasseveração que serve de título "constitui para nós uma dimensão que faz parte da identidade de um posicionamento discursivo" (MAINGUENEAU, 2011b, p. 72).

Há nos títulos das notícias em tela a instauração de uma cenografia que legitima as cenas genérica e englobante em um discurso que se propõe enunciar o que aconteceu no debate da BAND. Para se legitimar, a cenografia necessita que o outro, parceiro da enunciação, posicione-se como leitor da notícia, originando o discurso. Em tese, os títulos que deveriam ser uma síntese do debate possuem, cada um, uma forma específica de dar maior atenção a um ou outro fato, de interpretar a enunciação de uma forma e não de outra, de construir uma cenografia e não outra, que será sustentada durante todo o discurso. A interpretação do debate político é processada por um movimento de síntese que apaga grande parte dos acontecimentos do debate, uma vez que resume toda a enunciação.

\subsection{A MANUTENÇÃO DA CENOGRAFIA}

Em todas as notícias analisadas, a cena enunciativa se constrói, desde o início das notícias, em forma de introdução sobre os acontecimentos do debate. Acreditamos que, pela recorrência, isso pode ser uma característica da cena genérica (gênero notícia online), também marcada pela cena englobante do discurso (predominantemente político) narrado nas notícias. Vejamos os exemplos:

(2)

CARTA CAPITAL: "Lamento suas mil caras, Serra". Esse foi um dos motes do primeiro debate do segundo turno entre os candidatos à Presidência Dilma Rousseff (PT) e José Serra (PSDB). A petista não ficou na defensiva. Ao contrário, acuou o tucano em vários pontos: da campanha de calúnias na internet às privatizações no governo Fernando Henrique Cardoso, passando pela venda do banco Nossa Caixa para o Banco do Brasil.

A cenografia é construída pelo discurso citado, mas se sustenta nos comentários do decorrer das notícias. Essa sustentação da cenografia funciona por meio das escolhas lexicais que retomam a todo tempo a cenografia que se quer legitimar no discurso. No exemplo (2) de CARTA CAPITAL, um recorte da fala de Dilma é topicalizado na introdução, considerado "mote" do debate em tela. Toda a construção dessa introdução (que é uma manobra de síntese da enunciação) está relacionada à candidata Dilma Rousseff, de forma a interpretá-la como uma pessoa ativa no debate, que "acua" seu adversário e se "defende" de calúnias. As escolhas lexicais para a construção dessa cenografia, como "defensiva", "acuou", “adversário", lembram uma luta, um embate, uma disputa em que um ou outro será o vencedor. A cenografia criada pelo título evidenciado em (1) é sustentado pelas escolhas lexicais no texto em (2), no interior dos relatos e comentários sobre a fala de Dilma. 
A mesma cenografia de confronto foi criada pelo discurso de VEJA,

(3)

VEJA: Com apenas dois candidatos no palco, o debate presidencial na televisão renasceu neste domingo. José Serra (PSDB) e Dilma Rousseff (PT) se confrontaram de fato na Bandeirantes - com ideias e projetos, mas também procurando, cada um deles, minar a credibilidade do adversário.

Ao optar por "se confrontam", VEJA evidencia um embate entre os presidenciáveis. Opera-se uma retomada do título da notícia em que se lê "o debate presidencial na televisão renasceu neste domingo", exemplo (1), e incluem-se informações para que o leitor compreenda o porquê de o debate ter renascido. A interpretação é orientada tanto para o confronto entre os dois candidatos, quanto para a retomada dos debates anteriores, que eram, em grande medida, criticados pela mídia por não exporem ideias e projetos, como menciona VEJA.

O tom dos discursos é ainda direcionado para acusações entre os candidatos, reforçando a cenografia de confronto, ao informar ao leitor que a exposição das ideias e dos projetos acontecia com os dois candidatos, que procuravam "minar a credibilidade do adversário". Essa expressão não pode ser entendida como um ato passivo dos sujeitos políticos, mas como um ato ativo de um sujeito que se utiliza da fala para o ataque, para diminuir, abater a credibilidade do outro. Em (3), VEJA ainda não se posiciona em relação a um possível vencedor do debate, assim como não o fez no título em (1). O que podemos inferir do texto, ainda, é que há um renascimento justamente por causa do confronto e da ação de um candidato minar a credibilidade do outro. Se renasceu, é porque antes morreu ou deixou de existir.

A cenografia de luta pode ser ainda mais evidente, como acontece na construção discursiva do UOL:

(4)

UOL: A postura agressiva adotada por Dilma Rousseff no debate da Band provocou reações fortes de seus aliados e de seus adversários. Separados apenas por um corredor no auditório da emissora, petistas (do lado direito) e tucanos (do lado esquerdo) manifestaramse várias vezes durante o encontro com risos, vaias e comentários.

Em (4), UOL atribui à candidata um caráter de agressividade que teria desencadeado todo um clima bélico no debate político promovido pela BAND. Na descrição feita pelo site UOL, as reações foram negativas dos dois lados: tanto "petistas (do lado direito)" quanto "tucanos (do lado esquerdo)" se manifestaram, e essas manifestações ocorreram em forma de "risos, vaias e comentários". Como risos e vaias são pejorativos, compreendemos que os comentários, nesse sentido, também o são. Mantém-se, assim, a cenografia do debate como uma batalha.

As sínteses dos debates, presentes na introdução da notícia, constroem a cenografia na enunciação, na produção do discurso; isso é recorrente em todas as notícias que compreendem nosso corpus. A manutenção dessa cenografia, como podemos observar nos exemplos deste tópico, dá-se pelas escolhas lexicais que 
manifestam coerência no todo que a cenografia produz no discurso. Nesse sentido, os enunciados postos em relevo sob forma de títulos ou manchetes possuem um poder cenográfico: com traços discursivos mínimos eles evocam toda uma cenografia, que frequentemente não coincide com o texto destacado. Isso se justifica no trabalho de adequação realizado pela maquinaria midiática para adequar a notícia ao posicionamento do veículo de informação que a produz. Ao mesmo tempo em que a cenografia constrói a notícia, as notícias recenografam o debate político-televisivo ao adotar uma tomada de posição na construção do relato, e, assim, construir sua própria cenografia sobre o debate.

\subsection{MUDANÇA DE TOM}

No início deste artigo, levantamos algumas características relacionadas ao conceito de ethos discursivo, entre elas a de tom. Na produção da notícia online, o tom tem papel fundamental no direcionamento da cenografia que se quer construir. Em algumas situações, para se adequar ao posicionamento dos veículos de informação, procede-se ao apagamento de uma sobreasseveração realizada no calor da revolta, substituindo-a por um relato mais neutro e objetivo, num trabalho de inversão do tom. É o que verificamos em:

(5)

DILMA ROUSSEFF: [...] Agora, o que não está certo, por exemplo, é a sua esposa, a dona Mônica Serra, eu vou dizer o que ela falou, ela disse "a Dilma é a favor da morte de criancinhas". É tão absurda a acusação que mostra a característica desse processo, dessa campanha que é uma campanha contra mim e que usa uma coisa que o Brasil não tem, o ódio. (BAND)

TERRA: A candidata do PT concluiu seu ataque afirmando que esse tipo de tratamento traz para o Brasil algo que não é da característica do brasileiro.

A fala de Dilma em (5) se volta contra a acusação da esposa de José Serra sobre ela ser "a favor da morte de criancinhas". Nesse sentido, o tom do discurso da candidata petista é o de vitimização relativamente à acusação. Essa afirmação é confirmada quando Dilma atribui àquele discurso o "ódio". O tom está relacionado com o ethos construído no discurso de Dilma. A candidata se vitimiza pelas acusações, relacionando essa cenografia aos ataques frequentes a ela direcionados. A sobreasseveração do TERRA inverte esse tom de vitimização da candidata, dando à notícia um tom de ataque, que inverte também a cenografia.

Não podemos deixar de notar que a fala de Dilma, sob a forma de sobreasseveração, acentua que o ódio é uma "coisa que o Brasil não tem". O site TERRA fala em "algo que não é da característica do brasileiro". As duas falas se referem à mulher de José Serra, Mônica Serra, que é chilena. Por isso o ódio na fala de Dilma é direcionado a "uma coisa que o Brasil não tem" e que, supostamente, caracterizaria um estrangeiro. 
Essa interpretação não está acessível a todos, mas é facilitada pela sobreasseveração do TERRA, que apaga a palavra 'ódio' e a transforma em "tratamento", dizendo que é "algo" que não é da característica do brasileiro. Infere-se, portanto, que o "ódio" é da característica de outros povos que não os brasileiros e podese chegar à conclusão de que quem proferiu a pequena-frase "Dilma é favor da morte de criancinhas" não seja brasileira, mas a chilena Mônica Serra. Mesmo que essa informação não faça parte da memória dos leitores, ao dizer que o brasileiro não tem ódio, a candidata contribui para a criação de uma cenografia de vítima e põe em relevo um discurso do tipo incontestável, generalizante, sob o ponto de vista de um estereótipo de um povo cordial, que não tem ódio. Dessa forma, podemos interpretar que existe aqui uma confluência da sobreasseveração com a citação.

A referida citação remete, de certa forma, a Sérgio Buarque de Holanda (1995, p. 146) que caracteriza o brasileiro como "homem cordial", e afirma que "a contribuição brasileira para a civilização será de cordialidade". O autor informa que "cordial" vem de coração, portanto podemos relacionar essa característica com sentimentos como amor e perdão, em contraste com os sentimentos de ódio ou de vingança. Dilma Rousseff, em (5), apropria-se desse conceito de cordialidade, afastando o "ódio" do povo brasileiro, direcionando esse sentimento a estrangeiros, pessoas de outros países, como é o caso de Mônica Serra, esposa de seu rival.

A informação dada pelo site TERRA altera a fala de Dilma, como podemos perceber em (5), porém dizer que ter ódio "não é característica do brasileiro" facilita a interpretação que Dilma expõe em sua fala, "coisa que o Brasil não tem". Grande parte do eleitorado de Serra, acreditamos, pode fazer esse resgate e relacionar a mulher de Serra à outra nacionalidade e, portanto, ao "ódio".

\subsection{TRANSFORMAÇÃO DE DECLARAÇÃO EM INTERROGAÇÃO}

A transformação de uma frase afirmativa em outra interrogativa também se revela uma manobra que pode incidir em uma sobreasseveração, como vemos em:

(6)

DILMA ROUSSEFF: [...] eu sou contra tratar a questão das mulheres, das duas mulheres que morrem por dia, ou um dia sim um dia não, por aborto, como uma questão de polícia. Entre prender e atender, eu fico com atender. (BAND, grifo nosso)

CARTA CAPITAL: "O que vamos fazer com essas mulheres, atender ou prender?"

A fala de Dilma Rousseff, em (6), é uma sobreasseveração que, ao responder José Serra sobre um questionamento a respeito do aborto, resume todo seu discurso sobre a temática afirmando sua preferência por atender a prender. $\mathrm{O}$ discurso revela um tom de assistencialismo e remete a políticas públicas que amparem mulheres que praticaram o aborto. A pequena frase, que já beneficia a circulação desse enunciado, é modificada pela CARTA CAPITAL, que processa uma substituição do discurso afirmativo por um interrogativo. Mas, a sobreasseveração não perde sua força, ao ser transformada em pergunta: "O que devemos fazer com essas mulheres, atender ou prender?". 
Além do efeito de maior adesão, essa pergunta conclama o leitor a participar da afirmação de Dilma Rousseff. Esse tipo de pergunta é irrefutável, uma vez que ninguém ousaria optar por prender uma mulher que praticou o aborto e procura ajuda médica. Ao trazer o eleitor para participar dessa escolha, o veículo parece compartilhar da posição da candidata, assumindo a opção dela. Daí decorre uma mudança de sujeito, na alteração da sobreasseveração operada pela CARTA CAPITAL: Dilma, que havia falado em seu próprio nome, passa a ser um dentre todos os interlocutores que devem decidir o que fazer.

Essa manobra parece buscar a adesão dos eleitores que, frente a um questionamento como esse, estariam juntos com Dilma, ao mesmo tempo em que funciona como argumentação em relação às críticas levantadas por Serra sobre o aborto. É como se CARTA CAPITAL questionasse: você não concorda que se deve atender em vez de prender? Essa manobra discursiva de coparticipação do eleitor não se processa no exemplo a seguir:

\section{(7)}

JOSÉ SERRA: Sabe qual seria o Brasil do PT? O Brasil do orelhão, é o que a Dilma e o que seus amigos teriam feito caso tivessem o governo naquela época, porque ninguém teria celular. (BAND)

CARTA CAPITAL: "A era do PT seria a era do orelhão".

BAND: Para o tucano, sem a privatização da telefonia, o Brasil seria ainda o "país do orelhão".

Em (7), a questão que José Serra levanta é respondida por ele mesmo, não há alteração de destinatários. Tanto a BAND quanto a CARTA CAPITAL fazem as sobreasseverações sobre essa fala: "A era do PT seria a era do orelhão" e "o Brasil seria ainda o "país do orelhão". Devido à presença de um "nós inclusivo", a força pragmática do exemplo (6) é maior que o de (7), em que há apenas a mudança no tipo de frase. Portanto, a manobra de inclusão do leitor somada ao questionamento promove uma maior adesão.

\subsection{CIRCULAÇÃO E PRODUÇÃO DE PEQUENAS FRASES}

O discurso político, em geral, é profícuo na produção de pequenas frases, como pudemos perceber durante a análise. Nas notícias online que compõem nosso corpus, essas frases estão presentes com certa frequência. Isso nos permite observar que elas se manifestam nas citações em discurso direto com pequenas alterações que não as modificam, mas, pelo contrário, mantêm o sentido estabilizado que lhes dá vida.

(8)

JOSÉ SERRA: Olha é só chegar campanha eleitoral o PT volta sempre com essa história, só que ele é, como se dizia no Chile, como padre Gatica: predica e não pratica. (BAND)

TERRA: "O PT predica, mas não pratica", disse. 
O exemplo (8) de TERRA sintetiza em uma pequena-frase a posição do locutorfonte. Trata-se, portanto de uma citação. A troca da conjunção "e" pela conjunção "mas", na citação, não altera o sentido do enunciado, pois as duas relações são de contraste. A expressão "Padre Gatica: predica e não pratica" é de origem chilena; José Serra ficou exilado no Chile durante anos, onde, provavelmente, conheceu sua esposa. Esse provérbio é equivalente ao "faça o que eu digo e não o que eu faço", e ao atribuí-lo à candidata Dilma Rousseff, o efeito de sentido produzido é de um tom de falsidade, pois a fala da candidata não seria condizente com as suas atitudes, ela seria contraditória em suas afirmações.

A síntese de (8) também pode ser observada no exemplo que segue:

(9)

DILMA ROUSSEFF: [...] o professor pra ser valorizado, ele precisa de ganhar bem, e mais, ele precisa de ter formação continuada. Não se pode, também, estabelecer com o professor uma relação de atrito quando o professor pede melhores salários, recebê-los com cassetetes ou interromper o diálogo. O diálogo é fundamental no respeito a essa profissão. (GLOBO, grifo nosso)

ÉPOCA: Dilma aproveitou para atacar Serra quando ambos foram questionados sobre educação. Como já havia feito em outros debates, lembrou a relação crítica do governo do PSDB com a categoria, e a repressão às greves. "Não há diálogo ao se receber professor com cassetete". (grifo nosso)

Esses dois excertos em (9) demonstram que tanto os atores políticos quanto a maquinaria discursivo-midiática produzem pequenas frases. Nesses trechos, por meio de um processo de síntese, uma pequena frase, que é uma sobreasseveração, é produzida pelo site. "Não há diálogo ao se receber professor com cassetete" é uma pequena frase que não foi dita literalmente pela candidata, mas é apresentada entre aspas e atribuída a ela. Ou seja, a revista ÉPOCA atribui a Dilma uma sobreasseveração. É interessante notar que a candidata havia efetivamente produzido uma pequena frase, não a que o site colocou em circulação, mas outra: "O diálogo é fundamental no respeito a essa profissão". Da comparação entre as duas, concluímos que a sobreasseveração "atribuída" à candidata pela revista é mais enfática que a produzida por ela.

Com base nas discussões realizadas, podemos afirmar que o exemplo (8) é um caso de aforização (um ditado chileno), um enunciado destacado, autônomo, que é evocado na fala de Serra. A retomada de TERRA é uma sobreasseveração produzida na notícia e atribuída ao ator político. Por sua vez, o exemplo (9) é uma sobreasseveração, uma síntese de um posicionamento sob a forma de destaque efetuado pelo locutor-fonte (no caso, Dilma), que é alterado (para melhor) pelo site ÉPOCA.

\section{CONSIDERAÇÕES FINAIS}

Nossa análise nos mostrou que uma mesma citação de sobreasseveração pode sofrer diferentes manobras, atreladas às coerções da maquinaria discursivo-midiática. A opção por diferenciá-las neste trabalho é metodológica, uma vez que a separação nos permite um olhar mais aprofundado sobre os processos discursivos aí envolvidos, sem fechá-los em interpretações únicas. 
No batimento da análise, observamos que os enunciados em destaque fazem parte do mecanismo de uma sofisticada e complexa maquinaria discursivo-midiática, que produz e põe em circulação notícias online. As seleções, interpretações e torções efetuadas pelos veículos de informação na construção das notícias online evidenciam posicionamentos e cumprem uma necessidade pragmático-discursiva de adequação da enunciação à cenografia reconstruída pela notícia e ao ethos do veículo.

As manobras a que nos referimos mostraram-se características da maquinaria discursivo-midiática, fundamentais para a construção das notícias online, pois os destaques movimentam, silenciam, incluem, invertem sentidos e modificam contextos, e assumem posicionamentos que se relacionam a um público-leitor específico, delimitado pelo veículo de comunicação, e, também ele, parte integrante da engrenagem midiática.

Em nosso trabalho, observamos que embora o leitor da notícia online não tenha acesso ao texto-fonte (os debates político-televisivos), o que, para Maingueneau (2008a), caracteriza o destacamento efetuado nas notícias online como forte, não há necessidade de retornar ao original, porque se operam, na construção da notícia online, diferentes manobras que afastam ilusoriamente a possibilidade de o texto ser parcial. Desta forma, acreditamos que foi possível observar que as manobras discursivas que incidem sobre a construção da notícia online recenografam os debates políticotelevisivos.

\section{REFERÊNCIAS}

AMOSSY, R. Da noção retórica do ethos à análise do discurso. In: AMOSSY, R. (Org.). Imagens de si no discurso: a construção do ethos. Trad. Dilson Ferreira da Cruz, Fabiana Komesu e Sírio Possenti. São Paulo: Contexto, 2011. p. 9-28.

ASSIS, A. W. A. de. Citações e sobreasseverações: o funcionamento da retomada de falas em notícias online. 2013. 99f. Dissertação (Mestrado em Letras) - Programa de Pós-graduação em Letras, Universidade Estadual de Maringá, Maringá (PR), 2013.

AUTHIER-REVUZ, J. Hétérogénéité montrée et hétérogénéité constitutive: éléments pour une approche de l'autre dans le discours. DRLAV, Paris, n. 26, p. 91-151, 1982.

BAKHTIN, M. Estética da criação verbal. Trad. Paulo Bezerra. 4. ed. São Paulo: Martins Fontes, 2003. BERTRAND, C.-J. A deontologia das midias. Trad. Maria Leonor Loureiro. Bauru: EDUSC, 1999. CHARAUDEAU, p. Discurso das mídias. São Paulo: Contexto, 2012.

CITELLI, A. O texto argumentativo. São Paulo: Scipcione, 1994.

DOLZ, J.; SCHNEUWLY, B. Gêneros orais e escritos na escola. Trad. Roxane Rojo e Glaís Sales Cordeiro. São Paulo: Mercado de Letras, 2004.

GONÇALVES, C. A. V. Focalização no português do Brasil. 1997. 401f. Tese (Doutorado em Lingüística) - Faculdade de Letras, Universidade Federal do Rio de Janeiro, Rio de Janeiro, 1997. mimeo.

HOLANDA, S. B. Raizes do Brasil. 26. ed. São Paulo: Companhia das Letras, 1995.

KRIEG-PLANQUE, A. "Fórmulas" e "lugares discursivos": propostas para a análise do discurso político. In: MOTTA, A. R.; SALGADO, L. S. Fórmulas discursivas. São Paulo: Contexto, 2011. Entrevista concedida a Philippe Schepens. p. 11-40.

MAINGUENEAU, D. Pragmática para o discurso literário. São Paulo: Martins Fontes, 1996. . Novas tendências em Análise do Discurso. Campinas: Pontes, 1997.

Discurso Literário. São Paulo: Contexto, 2006.

. Cenas da enunciação. São Paulo: Parábola, 2008a. 
Gênese dos discursos. São Paulo: Parábola, 2008b.

Doze conceitos em análise do discurso. São Paulo: Parábola, 2010.

Análise de textos de comunicação. 6. ed. São Paulo: Cortez, 2011a.

Ethos, cenografia, incorporação. In: AMOSSY, R. (Org.). Imagens de si no discurso: a construção do ethos. Trad. Dilson Ferreira da Cruz, Fabiana Komesu e Sírio Possenti. São Paulo: Contexto, 2011b. p. 69-92.

MARTINEZ, A. G. A construção da notícia em tempo real. In: POLLYANA FERRARY, p. et alii. (Orgs.). Hipertexto hipermídia: as novas ferramentas da comunicação. São Paulo: Contexto, 2010. p. 13 28.

NOGUEIRA, L. Jornalismo na rede: arquivo, acesso, tempo, estatística e memória. In: FIDALGO, A.; SERRA, p. (Orgs.). Informação e comunicação online, Volume I - Jornalismo Online. Covilhã: Universidade da Beira Interior, 2003, p. 159-169.

POSSENTI, S. Pragmática na Análise do Discurso. Cadernos de Estudos Lingüísticos, n. 30, p. 71-84, Jan./Jun., 1996.

Questões para analistas do discurso. São Paulo: Parábola, 2009.

SOUZA-E-SILVA, M. C. Discursividade e espaço discursivo. In: FIGURO, Roseli (Org.). Comunicação e análise do discurso. São Paulo: Contexto, 2012, p. 99-118.

Recebido em: 08/05/13. Aprovado em: 16/12/13.

Title: A discursive machinery that remake the scene of the speach

Authors: André William Alves de Assis; Sonia Aparecida Lopes Benites

Abstract: Online news are full of overstatements, which, according to Maingueneau (2008a), imply stressing those emphases made by the interlocutor of the source-text. Within the context of social media functioning, overstatements are often ascribed to an interlocutor who did not give that special emphasis as reported in the source-text. It is often the case that the underscored enunciation in the source-text undergoes several changes and modifications. An analysis will be thus undertaken on the manner the reports of Bandeirantes and Globo TV-transmitted political debates on the second round of the 2010 Brazilian elections were reproduced in different online news. Results show discursive maneuverings through the construction of online news that remake the scene of the TV political debates.

Keywords: Overstatements. Quotes. Online news. Discursive maneuverings. Scenes.

Título: Una maquinaria discursiva de re-escenificar hablas

Autores: André William Alves de Assis; Sonia Aparecida Lopes Benites

Resumen: Las noticias online se muestran ricas en sobreaseveraciones, concepto que, de acuerdo con Maingueneau (2008a), implica el destaque hecho por el propio locutor del texto-fuente. No es difícil que en el funcionamiento mediático, el lugar del sobreaseverador sea imputado a un locutor que no hice aquel destaque en el texto-fuente. Todavía más común es la enunciación del sobreaseverado en el texto-fuente ser sometido a cambios de variadas órdenes. Con el objetivo de identificar casos en que una sobreaseveración es atribuida, en ausencia, a un locutor, y categorizar las maniobras discursivas visibles en las sobreaseveraciones, analizamos la forma como son relatados los debates políticotelevisivos de la Red Bandeirantes y de la Red Globo, del segundo turno de las elecciones de 2010, en cinco diferentes vehículos online. Nuestros resultados indican la existencia de maniobras discursivas propiciadas por la construcción de la noticia online que reescenifican los debates político-televisivos.

Palabras-clave: Sobreaseveración. Citación. Noticia online. Maniobras discursivas. Escenografía. 